\title{
Analysis Survival of Breast Cancer with Brain Metastases Treated with Different Fraction Whole Brain Radiotherapy Concomitant with Capecitabine
}

\author{
Rudiyo Yeoh ${ }^{1,2 \star}$, Iskandar Japardi ${ }^{3}$, Aznan Lelo ${ }^{4}$ (D, R. Susworo ${ }^{5}$, Jacub Pandelaki ${ }^{6}$ (D), Adang Bachtiar ${ }^{7}$, Suzy Indharty ${ }^{3}$, \\ Hendriyo Yeoh², Juli Jamnasi², William Omar ${ }^{2}$, Sudibio Sudibio ${ }^{2}$ (I) \\ ${ }^{1}$ Faculty of Medicine, Universitas Sumatera Utara, Medan, Indonesia; ${ }^{2}$ Department of Radiotherapy, Murni Teguh Memorial General \\ Hospital, Medan, Indonesia; ${ }^{3}$ Department of Neurosurgery, Haji Adam Malik General Hospital, Medan, Indonesia; ${ }^{4}$ Department of \\ Pharmacology and Therapy, Faculty of Medicine, Universitas Sumatera Utara, Medan, Indonesia; ${ }^{5}$ Gamma Knife Center, Cipto \\ Mangunkusumo National Central General Hospital, Jakarta, Indonesia; ${ }^{6}$ Department of Radiology, Cipto Mangunkusumo National \\ Central General Hospital, Jakarta, Indonesia, ${ }^{7}$ Faculty of Social Health, University of Indonesia, Jakarta, Indonesia
}

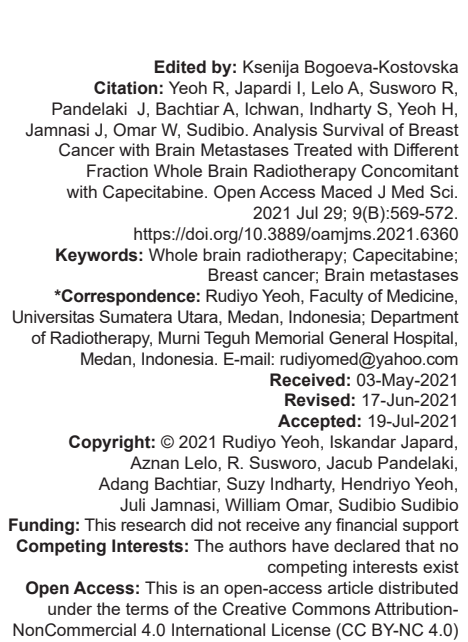

\section{Abstract}

BACKGROUND: Breast cancer is the second most frequent cancer worldwide. The main therapeutic modality for breast cancer with brain metastases is radiation. Whole-brain radiotherapy (WBRT) is a treatment that provides moderate doses of radiotherapy to all brain tissue. Capecitabine was found to be effective for the treatment of breast cancer with metastases and its metabolites can cross the bloodbrain barrier in animal models.

AIM: This study aims to determine the response and survival of breast cancer patient with brain metastases treated with different fractionation WBRT combined with capecitabine administration.

MATERIALS AND METHODS: This is a prospective, randomized-blind cohort analytic study. Patients were randomized into two groups by giving different fraction of WBRT (Group I WBRT $10 \times 3$ Gy and Group II WBRT $20 \times$ $2 \mathrm{~Gy}$ ) concomitant with capecitabine $850-1000 \mathrm{mg} / \mathrm{m}^{2}$. Overall survival (OS) was calculated from brain metastases diagnosis. Median follow-up was 5.6 months.

RESULTS: A total of 22 breast cancer patients with brain metastases participated in this study. Group I obtained results of $5(45.5 \%)$ out of 11 are responding to therapy and median OS was 4.4 months. Whereas in Group II found $11(100 \%)$ out of 11 patients responded to therapy and median OS was 9.4 months. The results of statistical analysis showed that there were significant differences of response between the two groups with $p=0.012$. The differences in survival of each group also statistically significant with $p=0.004$.

CONCLUSIONS: WBRT with $20 \times 2$ Gy concomitants with capecitabine gives a better response rate and OS.

\section{Introduction}

Breast cancer is the second most cancer in the whole world. About one in eight women (about 12\%) in the United States has breast cancer, 232,670 new cases in women and 2,360 new cases in men per year [1].

Brain metastases are found in about $10-16 \%$ of patients with breast cancer and have poor survival [2]. The main therapeutic modality for brain metastases is radiation. Whole-brain radiotherapy (WBRT) with a dose of 150-400cGy per day with a total dose reaching 3000-5000cGy provides an adequate dose of tumor [3].

Several studies have shown that the combination of chemotherapy and radiation can increase survival for 3-6 months [4]. Capecitabine was found to be effective for use in breast cancer with metastases [5]. Some studies say a limited amount of capecitabine, and its metabolites cross the bloodbrain barrier (BBB) in animal models [6].

There are no studies in Indonesia that have analyzed both the role of whole-brain radiation and the administration of capecitabine to breast cancer patients with brain metastases. This study aims to determine the effectiveness of WBRT on the response and overall survival (OS) of breast cancer brain metastatic lesions concomitant with capecitabine administration.

\section{Materials and Methods}

This study uses a prospective, randomizedblind, and cohort analytic study approach. Samples were patients with brain metastases and a history of 
previous breast malignancies who would undergo WBRT concomitant with capecitabine in Murni Teguh Hospital from January 2019 to August 2019, which met the inclusion and exclusion criteria. Patients with visceral metastases $>2$; have other primary malignancies; unwilling to participate in the study; have leptomeningeal or intra-tumoral bleeding; cystic lesions; get hormonal therapy or anti HER2; get less radiation than planned; and patients who take capecitabine irregularly were excluded from this study.

Patients were randomized into two groups by giving different fraction WBRT concomitant with capecitabine. Group I was the patient who received WBRT $10 \times 3 G y$ and capecitabine $850-1000 \mathrm{mg} / \mathrm{m}^{2}$. Group II were patients who received WBRT $20 \times 2$ Gy + capecitabine $850-1000 \mathrm{mg} / \mathrm{m}^{2}$. The patients were then evaluated 4 weeks post-radiation by computed tomography scan or magnetic resonance imaging with contrast. The measurement results are divided into two, responder and nonresponder groups. Categorized as a responder group if a complete response was found (loss of all intra-cranial lesion targets with no evidence of tumor anywhere) or a partial response (at least a reduction of at least $30 \%$ of all tumor measurements), and non responder group if stable disease or progressive disease. OS was calculated from brain metastases diagnosis. Patients who were alive at the end of the study were censored from analysis.

Statistical analysis was done using SPSS 23.0. Analysis of differences in respondent characteristics and responses of brain metastatic breast cancer patients receiving WBRT and capecitabine combination therapy were performed using the Chi-square test if the data were normally distributed or Fischer exact if the data were not normally distributed. OS was calculated using the Kaplan-meier method, and prognostic factors were determined by log-rank test. Cox proportional hazards model was used for multivariate analysis. $p<0.05$ indicate statistical significance.

This study was approved by the health research ethical committee medical faculty of Universitas Sumatera Utara/H.Adam Malik general hospital.

\section{Results}

A total of 22 breast cancer patients with brain metastases participated in this study. Patients were divided into two groups. Eleven patients in each group. The characteristics of patients in the both arms are summarized in Table 1.

The characteristics of the research patients, the variables of age, KPS, PA, and IHC showed no significant correlation to therapeutic response. The characteristics that shown significant correlation were OTT and number of lesions as shown in Table 2.
Table 1: Characteristics of patients

\begin{tabular}{|c|c|c|c|c|c|c|c|}
\hline \multirow[t]{2}{*}{ Characteristics } & \multicolumn{2}{|c|}{$\begin{array}{l}\text { Group } 1 \\
(10 \times 3 \text { Gy })\end{array}$} & \multicolumn{2}{|c|}{$\begin{array}{l}\text { Group } 2 \\
(20 \times 2 \text { Gy })\end{array}$} & \multicolumn{2}{|c|}{ Total } & \multirow[t]{2}{*}{ p-value* } \\
\hline & $\mathrm{n}$ & $\%$ & $\mathrm{n}$ & $\%$ & $\mathrm{n}$ & $\%$ & \\
\hline \multicolumn{8}{|l|}{ Age } \\
\hline$<50$ & 5 & 38.5 & 8 & 61.5 & 13 & 100 & \multirow[t]{2}{*}{0.387} \\
\hline$\geq 50$ & 6 & 66.7 & 3 & 33.3 & 9 & 100 & \\
\hline \multicolumn{8}{|c|}{ Overall Treatment Time (OTT) } \\
\hline$<20$ days & 11 & 100 & 0 & 0 & 11 & 100 & \multirow[t]{2}{*}{$<0.001$} \\
\hline$\geq 20$ days & 0 & 0 & 11 & 100 & 11 & 100 & \\
\hline \multicolumn{8}{|l|}{ KPS } \\
\hline$<70$ & 6 & 75 & 2 & 25 & 8 & 100 & \multirow[t]{2}{*}{0.183} \\
\hline$\geq 70$ & 5 & 35.7 & 9 & 64.3 & 14 & 100 & \\
\hline \multicolumn{8}{|l|}{ Lesions } \\
\hline$\leq 3$ & 4 & 33.3 & 8 & 66.7 & 12 & 100 & \multirow[t]{2}{*}{0.087} \\
\hline$>3$ & 7 & 70 & 3 & 30 & 10 & 100 & \\
\hline \multicolumn{8}{|l|}{ PA } \\
\hline Invasive Ductal Ca & 11 & 50 & 11 & 50 & 22 & 100 & \multirow[t]{2}{*}{1} \\
\hline Invasive Lobular $\mathrm{Ca}$ & 0 & 0 & 0 & 0 & 0 & 0 & \\
\hline \multicolumn{8}{|l|}{$\mathrm{IHC}$} \\
\hline ER+, PR+, HER2- & 1 & 50 & 1 & 50 & 2 & 100 & \multirow[t]{5}{*}{0.534} \\
\hline $\mathrm{ER}+, \mathrm{PR}+, \mathrm{HER} 2+$ & 0 & 0 & 2 & 100 & 2 & 100 & \\
\hline ER-, PR-, HER2+ & 4 & 57.1 & 3 & 42.9 & 7 & 100 & \\
\hline ER-, PR-, HER2- & 1 & 100 & 0 & 0 & 1 & 100 & \\
\hline No examination & 5 & 50 & 5 & 50 & 10 & 100 & \\
\hline
\end{tabular}

The results of responses to WBRT and capecitabine showed significant differences between groups. Group I (WBRT 10 × 3Gy + capecitabine 850 $1000 \mathrm{mg} / \mathrm{m}^{2}$ ) obtained results of $5(45.5 \%)$ responding to therapy. Whereas in group II (WBRT $20 \times 2 \mathrm{~Gy}$ + capecitabine $850-1000 \mathrm{mg} / \mathrm{m}^{2}$ ) found $11(100 \%)$ patients responded to therapy. The results of statistical analysis showed that there were significant differences between the two groups with a $p=0.012$ as shown in Table 3.

Table 2: The correlation between patient characteristic and therapeutics response

\begin{tabular}{|c|c|c|c|c|c|c|c|}
\hline \multirow[t]{2}{*}{ Characteristics } & \multicolumn{2}{|c|}{ Responder } & \multicolumn{2}{|c|}{ Non-Responder } & \multicolumn{2}{|c|}{ Total } & \multirow[t]{2}{*}{ p-value* } \\
\hline & $\mathrm{n}$ & $\%$ & $\mathrm{n}$ & $\%$ & $\mathrm{n}$ & $\%$ & \\
\hline \multicolumn{8}{|l|}{ Age } \\
\hline$<50$ & 9 & 69.2 & 4 & 30.8 & 13 & 100 & \multirow[t]{2}{*}{1} \\
\hline$\geq 50$ & 7 & 77.8 & 2 & 22.2 & 9 & 100 & \\
\hline \multicolumn{8}{|l|}{ Overall Treatment Time } \\
\hline$<20$ days & 5 & 45.5 & 6 & 54.5 & 11 & 100 & \multirow[t]{2}{*}{0.012} \\
\hline$\geq 20$ days & 11 & 100 & 0 & 0 & 11 & 100 & \\
\hline \multicolumn{8}{|l|}{ KPS } \\
\hline$<70$ & 6 & 75 & 2 & 25 & 8 & 100 & \multirow[t]{2}{*}{1} \\
\hline$\geq 70$ & 10 & 71.4 & 4 & 28.6 & 14 & 100 & \\
\hline \multicolumn{8}{|l|}{ Lesions } \\
\hline$\leq 3$ & 12 & 100 & 0 & 0 & 12 & 100 & \multirow[t]{2}{*}{0.003} \\
\hline$>3$ & 4 & 40 & 6 & 60 & 10 & 100 & \\
\hline \multicolumn{8}{|l|}{ PA } \\
\hline Invasive Ductal Ca & 0 & 0 & 0 & 0 & 0 & 0 & \multirow[t]{2}{*}{$0.00^{\mathrm{a}}$} \\
\hline Invasive Lobular $\mathrm{Ca}$ & 16 & 72.7 & 6 & 27.3 & 22 & 100 & \\
\hline \multicolumn{8}{|l|}{ IHC } \\
\hline ER+, PR+, HER2- & 2 & 100 & 0 & 0 & 2 & 100 & \multirow[t]{5}{*}{0.233} \\
\hline ER+, PR+, HER2+ & 2 & 100 & 0 & 0 & 2 & 100 & \\
\hline ER-, PR-, HER2+ & 6 & 85.7 & 1 & 14.3 & 7 & 100 & \\
\hline ER-, PR-, HER2- & 0 & 0 & 1 & 100 & 1 & 100 & \\
\hline No examination & 6 & 60 & 4 & 40 & 10 & 100 & \\
\hline
\end{tabular}

Median survival for the entire cohort was 6.8 months, with the median follow-up was 5.6 months. Median survival for Group 1 and Group 2 were 4.4 months and 9.4 months, respectively, $(p=0.004)$ as shown in Figure 1.

Table 3: The result of response

\begin{tabular}{|c|c|c|c|c|c|c|c|}
\hline \multirow[t]{2}{*}{ Group } & \multicolumn{2}{|c|}{ Responder } & \multicolumn{2}{|c|}{ Non-Responder } & \multicolumn{2}{|c|}{ Total } & \multirow[t]{2}{*}{ p-value* } \\
\hline & $\mathrm{n}$ & $\%$ & $\mathrm{n}$ & $\%$ & $\mathrm{n}$ & $\%$ & \\
\hline WBRT 10×3Gy & 5 & 45.5 & 6 & 54.5 & 11 & 100 & 0.012 \\
\hline WBRT $20 \times 2 G y$ & 11 & 100 & 0 & 0 & 11 & 100 & \\
\hline Total & 16 & 72.7 & 6 & 27.3 & 22 & 100 & \\
\hline
\end{tabular}

The impact of various related factors on OS is described in Table 4 . In the univariate analysis using log-rank test, patients with age $>50$, KPS $<70$, number 


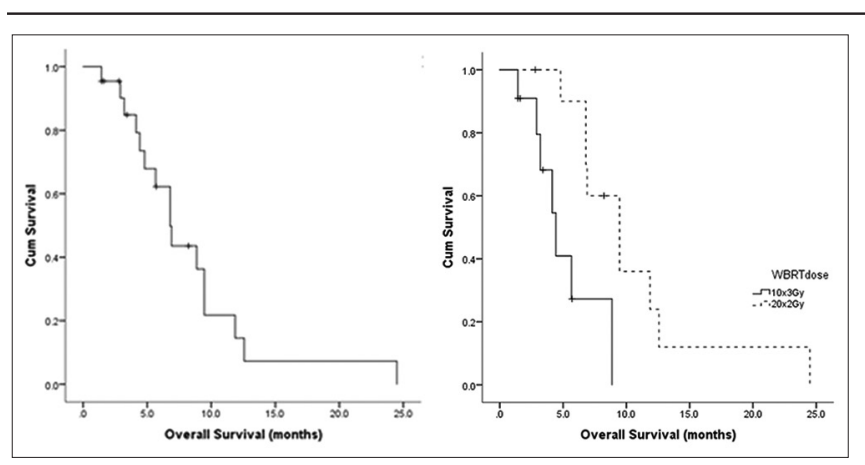

Figure 1: Overall survival for the entire cohort and each group

of lesions $>3$, OTT $\leq 20$ days, and nonresponders group had worse survival as shown in Table 4 . In the multivariate analysis using cox proportional hazards, OTT > 20 was found to be independent factors affecting OS as shown in Table 5.

Table 4: Factors affecting OS in the univariate analysis

\begin{tabular}{lllll}
\hline Variables & Median OS (months) & HR & $95 \% \mathrm{Cl}$ & p-value \\
\hline $\begin{array}{l}\text { Age } \\
\quad 50\end{array}$ & 8.8 & & & \\
$\quad>50$ & 4.4 & 0.33 & $0.09-1.21$ & 0.07 \\
$\begin{array}{l}\text { Lesion } \\
\leq 3\end{array}$ & 8.8 & Ref & & \\
$\quad>3$ & 6.8 & 0.54 & $0.18-1.54$ & 0.23 \\
KPS & & Ref & & \\
$\quad 70$ & 5.6 & & & \\
$\quad>70$ & 6.9 & 2.48 & $0.82-7.46$ & 0.86 \\
OTT & & Ref & & \\
$\quad \leq 20$ days & 4.4 & & & \\
$\quad>20$ days & 9.4 & ref & & \\
$\quad$ Response & & & & \\
$\quad$ Non Responder & 4.4 & ref & & 0.004 \\
$\quad$ Responder & 8.8 & 3.58 & $0.75-17.01$ & \\
\hline OTT: Overall treatment time, OS: Overall survival. & & &
\end{tabular}

\section{Discussion}

WBRT remains the mainstay of palliative treatment for most patients with brain metastasis from breast cancer, which produces symptomatic relief. WBRT also can improve survival and quality of life and radiologic response in several cases [7]. However, the relatively suboptimal results of WBRT alone in the eradication of brain metastases have led to studies combining radiotherapy with chemotherapy drugs that could act as radiosensitizers with a rationale of improving local tumor control.

Table 5: Factors affecting $O S$ in the multivariate analysis

\begin{tabular}{llll}
\hline Variables & aHR & $95 \% \mathrm{Cl}$ & $\mathrm{p}$-value \\
\hline Age $(>50)$ & 2.81 & $0.64-12.27$ & 0.24 \\
Lesions $(>3)$ & 2.31 & $0.57-9.37$ & 0.29 \\
OTT $(>20)$ & 0.20 & $0.04-0.92$ & 0.03 \\
Non Responder & 1.41 & $0.17-11.18$ & 0.89 \\
\hline OTT: Overall treatment time, OS: Overall survival. & &
\end{tabular}

Capecitabine is an oral tumor-activated fluoropyrimidine carbamate. This prodrug is absorbed across the gastrointestinal mucosa, then converted to 5 -FU via thymidine phosphorylase. lonizing radiations have been shown to preferentially increase tumor thymidine phosphorylase levels via induction of tumor necrosis factor [8]. Pharmacokinetic studies have shown that limited amounts of capecitabine and its metabolites cross the BBB in animal models [6]. Disruption of the brainblood barrier by the metastatic process in brain metastases may allow a higher concentration of active drugs in intracranial tumors via the circulation. The combination of a single photon irradiation with capecitabine was much more effective than either radiation or chemotherapy alone in mammary human cancer xenograft models. Their efficacy in tumor growth inhibition appeared to be additive, but the combination delayed tumor growth to a much greater extent than did either treatment alone [9]. Several cases in which brain metastases from breast cancer responded to treatment with oral capecitabine have been reported [10], [11]. Capecitabine monotherapy also reported can achieve a complete response in three patients and long-term control in all patients with both leptomeningeal and parenchymal brain metastases from breast cancer [12].

In this study, there were more responders in Group 2 and also had a better overall survival than group 1. By giving WBRT $20 \times 2 \mathrm{~Gy}$, then the dose of capecitabine will also increased, the radiosensitizer effect will also increase during WBRT. In a case series, WBRT $10 \times 3 \mathrm{~Gy}$ concomitant with capecitabine $1000 \mathrm{mg} / \mathrm{m}^{2}$ obtained $60 \%$ responder results [13]. WBRT $20 \times 2 \mathrm{~Gy}$ is a well-tolerated and considered in patients, especially in a good performance status with single metastases or even with multiple brain metastases [14]. In this study, it showed that the responder group had better OS than non-responder group.

There are some limitations in this study. The follow-up of this study is not very long because it was influenced by patient's socioeconomic problems. Because most patients come from out of town and are required to stay near the hospital during therapy. Patients must find a place to stay and eat alone. Another factor is family support, because it is far from the place of origin, so support from the family is also very little. The availability of resources in Indonesia is also very limited, where the linear accelerator that can deliver stereotactic radiosurgery (SRS) or stereotactic radiotherapy (SRT) technique is also limited. Because of this limitation, this study uses WBRT. The dose of the capecitabine used in this study was $850-1000 \mathrm{mg} / \mathrm{m}^{2}$ because the drug preparations in Indonesia are only $500 \mathrm{mg}$. Abroad, there are two preparations of capecitabine, $(150 \mathrm{mg}$ and $500 \mathrm{mg}$ ).

\section{Conclusions}

In this study, the administration of capecitabine and $20 \times 2$ Gy fractions gave a better response and OS both clinically and statistically. 


\section{Recommendation}

It is recommended to provide $500 \mathrm{mg} / \mathrm{tablet}$ and $150 \mathrm{mg} /$ tablet capecitabine preparation and linear accelerator devices that can do SRS/SRT technique in Indonesia.

\section{References}

1. American Cancer Society. Cancer Treatment and Survivorship Facts and Figures. United States: American Cancer Society; 2014.

2. Lu J, Steeg PS, Price JE, Krishnamurthy S, Mani SA, Reuben J, et al. Breast Cancer metastasis: Challenges and opportunities. Cancer Res. 2009;69(12):4951-3. https://doi.org/10.1158/00085472.can-09-0099

PMid: 19470768

3. Devita VT, Lawrence TS, Rosenberg SA. Brain metastasis. In: Cancer Principles and Practice of Oncology. $9^{\text {th }}$ ed. Netherlands: Wolters Kluwer India Pvt. Ltd.; 2011.

4. Patchell R, Regine W. Brain metastase: Whole brain radiation therapy perspective. In: Principles and Practice of Stereotactic Radiosurgery. Berlin, Germany: Springer; 2008. p. 201-5. https://doi.org/10.1007/978-0-387-71070-9_16

5. Rivera E, Meyers C, Groves M, Valero V, Francis D, Arun B, et al. Phase I study of capecitabine in combination with temozolomide in the treatment of patients with brain metastases from breast carcinoma. Cancer. 2006;107(6):1348-54. https:// doi.org/10.1002/cncr.22127 PMid:16909414

6. McEvoy G. Capecitabine. In: AHFS Drug Information Bethesda, MD: American Society of Health-system Pharmacists; 2002. p. 916-21.

7. Gaspar L, Scott C, Rotman M, Asbell S, Phillips T, Wasserman T, et al. Recursive partitioning analysis (RPA) of prognostic factors in three radiation therapy oncology group (RTOG) brain metastases trials. Int J Radiat Oncol. 1997;37(4):745-51. https:// doi.org/10.1016/s0360-3016(96)00619-0

PMid:9128946

8. Seiwert TY, Salama JK, Vokes EE. The concurrent chemoradiation paradigm-general principles. Nat Clin Pract Oncol. 2007;4(2):86-100. https://doi.org/10.1038/ncponc0714 PMid:17259930

9. Sawada N, Ishikawa T, Sekiguchi F, Tanaka Y, Ishitsuka H. X-ray irradiation induces thymidine phosphorylase and enhances the efficacy of capecitabine (Xeloda) in human cancer xenografts. Clin Cancer Res. 1999;5(10):2948-53.

PMid:10537364

10. Wang ML, Yung WK, Royce ME, Schomer DF, Theriault RL. Capecitabine for 5-fluorouracil-resistant brain metastases from breast cancer. Am J Clin Oncol. 2001;24(4):421-4. https://doi. org/10.1097/00000421-200108000-00026 PMid:11474279

11. Fabi A, Vidiri A, Ferretti G, Felici A, Papaldo P, Carlini $P$, et al. Dramatic regression of multiple brain metastases from breast cancer with capecitabine: Another arrow at the bow? Cancer Invest. 2006;24(4):466-8. https://doi. org/10.1080/07357900600705805 PMid:16777702

12. Ekenel M, Hormigo AM, Peak S, DeAngelis LM, Abrey LE. Capecitabine therapy of central nervous system metastases from breast cancer. J Neurooncol. 2007;85(2):223-7. https://doi. org/10.1007/s11060-007-9409-0

PMid:17611719

13. Chargari C, Kirova YM, Diéras V, Pena PC, Campana F, Cottu $\mathrm{PH}$, et al. Concurrent capecitabine and whole-brain radiotherapy for treatment of brain metastases in breast cancer patients. J Neurooncol. 2009;93(3):379-84. https://doi.org/10.1007/ s11060-008-9791-2

PMid: 19169856

14. Noordijk EM, Vecht CJ, Haaxma-Reiche H, Padberg GW, Voormolen $\mathrm{JH}$, Hoekstra $\mathrm{FH}$, et al. The choice of treatment of single brain metastasis should be based on extracranial tumor activity and age. Int J Radiat Oncol. 1994;29(4):711-7. https:// doi.org/10.1016/0360-3016(92)90169-i

PMid:8040016 